Economic Computation and Economic Cybernetics Studies and Research, Issue 3/2018; Vol. 52

\author{
Professor Xia CAO, PhD \\ E-mail: 1055305651@qq.com \\ Student Zeyu XING, PhD \\ E-mail: xingzeyusmile@163.com;xingzeyu@hrbeu.edu.cn \\ School of Economics and Management \\ Harbin Engineering University
}

\title{
THE STRATEGY OPTIONS OF ENERGY-SAVING AND ENVIRONMENTAL PROTECTION INDUSTRY UNDER INCOMPLETE INFORMATION: A TRIPARTITE GAME ANALYSIS OF GOVERNMENT, ENTERPRISES AND FINANCIAL INSTITUTIONS
}

\begin{abstract}
Government and financial institutions play important roles in developing well-designed policies to drive energy-saving and environmental protection industrial innovation into product sustainability performance. The research method adopted in this study includes a tripartite game to study the likely strategy options of three stakeholders. We then study the effect of government incentives and regulations and financial institutions policies on the diffusion of enterprises' production strategies. In contrast to the existing research, we use evolutionary game theory to consider the behavior of government, enterprises and financial institutions in terms of the diffusion of different strategies and expound on this issue in combination with replicator dynamic theory to make the conclusions more general, thereby providing insight into the design of sustainability policies that promote energy-saving and environmental protection industrial development.
\end{abstract}

Keywords: Evolutionary game model; Tripartite game analysis; Replicator dynamic theory; Energy-saving and environmental protection.

JEL Classification: C73, C83, C88, H25, O32, O33, 038.

\section{Introduction}

With the increasing ecological problems of environmental pollution, resource depletion and energy shortage in the world, calculation and control analysis of energy-saving and environmental protection have attracted many of attention from various fields of researchers. People are gradually aware that Global action is of DOI: $10.24818 / 18423264 / 52.3 .18 .13$ 
great necessity and have reached an agreement for "responsibilities sharing" (Ping et. al., 2015). Government has considerably enhanced pollution control and environmental protection in both developed countries like US(Langpap and Shimshack, 2010) or Japan (Cole et. al., 2013) and in the developing economics like India(Kathuria, 2007) or China (Lian et. al., 2016). Especially in China, central government has issued a series of plans and regulations, including The Development Plan of Energy Saving and Environmental Protection Industry in 12th Five-Year (2012), New Environmental Law (2015), Action Plan For Soil Environmental Protection and Pollution Control (2016), The Development Plan of Energy Saving and Environmental Protection Industry in 13th Five-Year (2016), etc. On the one hand, these policies offer supporting for the enterprises produce energy-saving and environmental protection products (hereafter referred to as green products) via government regulation, subsidies and tax preferences. On the other hand, financial institutions are increasingly paying attention towards investments flowing into energy-saving and environmental protection projects, thus contributing to the fostering of the development of a more environmentally sustainable economy (Pasquale et. al., 2017).

Enterprises are also important stakeholders in energy-saving and environmental protection(Rui et. al., 2016). Investigations of the sales of green products have shown that consumers would like to pay more for green products(Zhao et. al., 2014). Therefore, enterprises need to promote innovation and satisfy demand for eco-friendly products to capture market share (Lin et. al., 2013). However, the extra cost of technology innovation, market risk, and complicated external environment may result in uncertainty regarding commercial success (Bi et. al., 2015). This paper, government plays a leading role in developing well-designed policies to drive energy-saving and environmental protection industrial innovation into product sustainability performance (Choi, 2015). We identify financial institutions also as key stakeholders because a number of institutions participate in industrial innovation, and offer subsidies to enterprises that produce green products. Sustainable performance needs cooperation among all participating agents to work together to create a win-win outcome. However, it is difficult to visualize the strategy of every player, such as trustworthy, opportunism, honesty and so on. Besides, about the researches of energy-saving and environmental protection industrial innovation just focus on the two stakeholders (enterprises and consumers, or enterprises and government) evaluation, and few of them can further evaluate the 
The Strategy Options of Energy-Saving and Environmental Protection Industry under Incomplete Information

possibility of coordination between the three stakeholders (included financial institutions, government and enterprises).Given above context, we attempt to adopt an evolutionary game to study the likely strategy options of three stakeholders, thereby providing insight into the design of sustainability policies that promote energy-saving and environmental protection industrial development.

\section{Background and related work}

Energy-saving and environmental protection is a complex system, which includes energy-saving, resources recycling and environmental protection. The energy-saving and environmental protection mechanism consists of strategy selection and internal implementation of the enterprises and the external channels. Some previous studies focus on the evolution of the industry (Myeong et. al., 2014),technical innovation costs (Tian and Jin, 2012), influential factors (Constantinos et. al., 2017), and route planning of industry systems (Fang et. al., 2012). These study focus on the internal or external factors. Foremost, government policies option should be concerned (Guo and $\mathrm{Fu}, 2010$ ). For example, some scholars (Lorek and Spangenberg, 2014) explored energy-saving and environmental protection incentive policies. Someone (Zhao et. al., 2014) emphasized the importance of government subsidy policies. Also someone(Liu et. al., 2015) investigated the effects of tax preferences on enterprises that produce green products. However, scholars pointed out that the effectiveness of tax and subsidy policies depended on the specific situation. They(Ma and Yu, 2017) concluded that modest regulations were important in the energy-saving and environmental protection industry. Given these studies, what financial policies can be implemented to boost the energy-saving and environmental protection industry sector? We find this study is rarely (Liu et. al., 2017).

Industrial development is a process of benefit redistribution, which is essentially suitable for game analysis of involved stakeholders(Bao et. al., 2015). Game theory is often seen as an essential tool when dealing with energy-saving and environmental protection problems with multiple agents. The application of game to the energy-saving and environmental protection has been discussed by a number of works (Liang et. al., 2016). However, these studies usually assumed that the stakeholder is rational, and can get whole information, which are inconsistent in practice. The evolutionary game focuses on the interaction among different stakeholders, the main idea of the evolutionary game is to find the frequencies of strategies selected during the evolutionary game process. The equilibrium and stable

DOI: $10.24818 / 18423264 / 52.3 .18 .13$ 
strategy was discussed by a replicator dynamic system. Finally, the optimized strategy was achieved by the process of dynamic game evolution.In recently, someone developed an evolutionary game model between the government and enterprises in the energy-saving and environmental protection industry, the findings suggest that enterprises' expectation of government behaviors including incentive and regulation determines whether green strategies can be diffused, and the diffusion speed (Wu et. al., 2017). The more quick enterprises adjust their strategy in the government-enterprise game, the more enterprises will learn and follow to adopt effective green strategy, when enterprises attach great importance to the expected earnings from government incentives. Also, other researchers have studied of two stakeholders in energy-saving and environmental protection industry (Tian et. al., 2014). However, few of them can further evaluate the possibility of coordination between the three stakeholders, included financial institutions.

The research method adopted in this study includes a tripartite game to study the likely strategy options of three stakeholders. We then study the effect of government incentives and regulations and financial institutions policies on the diffusion of enterprises' production strategies. In contrast to the existing research, we use evolutionary game theory to consider the behavior of government, enterprises and financial institutions in terms of the diffusion of different strategies and expound on this issue in combination with replicator dynamic theory to make the conclusions more general.

\section{Game model and assumptions}

\subsection{The evolutionary game relationships}

The innovation of energy-saving and environmental protection industry is mainly impacted by three drivers which are government, enterprises and financial institutions. The government can select from two strategies: positively guiding the industry development (we can call "positive") and inactively intervening industrial development, just supervise ("negative"). In the situation of "positive", the government provides the tax preferences for the enterprises that produce green products as well as issue a series of green finance policies for the financial institutions. In the case of "negative", the government just supervises the enterprises that do not produce green products. The strategies that can be selected by enterprises include: active produce green products and response to the government policies and financial institutions support ("production"), or negative joining industrial development and do not produce green products ("non-production"). Financial 
The Strategy Options of Energy-Saving and Environmental Protection Industry under Incomplete Information

institutions also face two choices: supporting energy-saving and environmental protection industry ("participation") or indifferent ("non-participation").The game relationships can be shown in Figure 1.

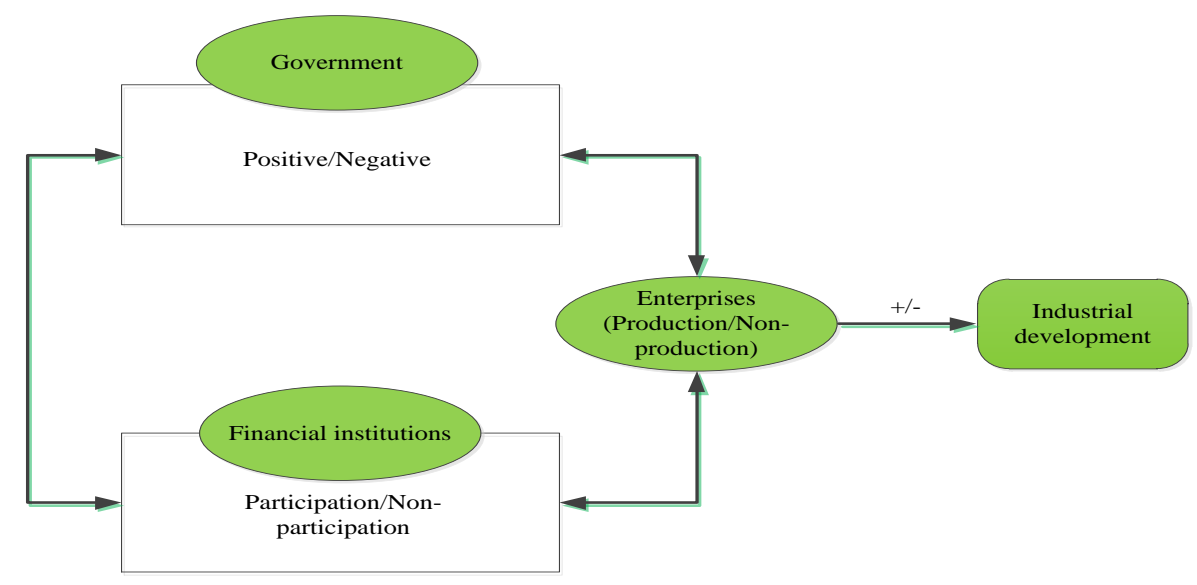

Figure1.The game relationships among the government, enterprises, and financial institutions

\subsection{Assumptions}

(1) In the energy-saving and environmental protection system, there are three players: government, enterprises and financial institutions.

(2) The various game players have limited rationality because they have incomplete information and thus cannot make a choice that maximizes their own interests. Each stakeholder has learning and imitative abilities and can adjust their own strategy according to experience. See the Table 1.

\section{Table1}

\section{Model parameters and connotations}

Parameters Connotations

W The increase of social welfare when government selects positive strategy

$\mathrm{T}$ The tax preferences for the enterprises

$\beta C_{2}$ Government' execute costs for the enterprises, $\beta$ is degree

$\gamma C_{3}$ Government costs for the financial, $\gamma$ is degree

$r_{1}$ The government benefits when financial institutions select participation

DOI: $10.24818 / 18423264 / 52.3 .18 .13$ 
$r_{2}$ The government benefits when financial institutions select non-participation $\alpha C_{1}$ The supervision costs, this degree is $\alpha$

$R_{1}$ The enterprises' benefits when adopts the production strategy

$R_{2}$ The enterprises' benefits when adopts the non- production strategy

$c$ The research costs when adopts production strategy

$S$ The loss of benefits when government selects negative strategy

$F_{2}$ The enterprises' benefits when enterprises adopt production and financial institutions select participation strategy

$F_{3}$ The extra benefits for the enterprises when enterprises adopt non-production and financial institutions select participation strategy

$C_{4}$ Financial institutions' costs for the enterprises select production

$C_{5}$ Financial institutions' costs for the enterprises select non-production

$F_{1}$ The benefits granted with the government issues a series of green financial policies

$P_{1}$ The extra benefits for the financial institutions when financial institutions select participation

$P_{2}$ The reputation costs of financial institutions when financial institutions select non-participation under the government adopts positive strategy

\section{Equilibrium analysis of evolutionary game}

\subsection{The expected earnings and replicator dynamic analysis of each} stakeholder

The earnings matrix among three players is established in Table 2. In the Table 
The Strategy Options of Energy-Saving and Environmental Protection Industry under Incomplete Information

$2, a_{i}, b_{i}$, and $c_{i}$ represents the earnings of government, enterprises and financial institutions, where

$$
\begin{gathered}
\left(a_{1}, b_{1}, c_{1}\right)=\left(W-\beta C_{2}-\gamma C_{3}+r_{1}, R_{1}+T+F_{2}-c, P_{1}+F_{1}-C_{4}\right) \\
\left(a_{2}, b_{2}, c_{2}\right)=\left(W-\gamma C_{3}+r_{1}, R_{2}+F_{3}, P_{1}+F_{1}-C_{5}\right) \\
\left(a_{3}, b_{3}, c_{3}\right)=\left(r_{2}, R_{1}+F_{2}-c, P_{1}-C_{4}\right) \\
\left(a_{4}, b_{4}, c_{4}\right)=\left(r_{2}+S-\alpha C_{1}, R_{2}+F_{3}-S, P_{1}-C_{5}\right) \\
\left(a_{5}, b_{5}, c_{5}\right)=\left(W-\beta C_{2}-\gamma C_{3}, R_{1}+T-c, F_{1}-P_{2}\right) \\
\left(a_{6}, b_{6}, c_{6}\right)=\left(W-\gamma C_{3}, R_{2}, F_{1}-P_{2}\right) \\
\left(a_{7}, b_{7}, c_{7}\right)=\left(0, R_{1}-c, 0\right) \\
\left(a_{8}, b_{8}, c_{8}\right)=\left(S-\alpha C_{1}, R_{2}-S, 0\right)
\end{gathered}
$$

In the initial stage of the three-player game, suppose that the proportion of government departments choosing positive is $x$, and the proportion choosing negative is 1-x. Simultaneously, suppose that the proportion of enterprises that select production strategy is $y$, and the proportion selecting non-production is $1-y$. Suppose also that the proportion of financial institutions selecting participation is $z$, and the proportion selecting non-participation is $1-z$. Where $0 \prec x \prec 1,0 \prec y \prec 1,0 \prec z \prec 1$.

Supposing that $E_{11}$ represents the expected earnings of the government departments that adopt positive strategy, $E_{12}$ represents the expected earnings of the government that adopt negative strategy, and $\bar{E}_{1}$ represents the expected earnings of government departments that adopt the two strategies. Then:

$$
\begin{aligned}
& E_{11}=y z a_{1}+(1-y) z a_{2}+y(1-z) a_{5}+(1-y)(1-z) a_{6} \\
& E_{12}=y z a_{3}+\left(1-y \quad z q+(y-) z{ }_{7} a(+1-)(y) z\right.
\end{aligned}
$$

\section{DOI: $10.24818 / 18423264 / 52.3 .18 .13$}




$$
\bar{E}_{1}=x E_{11}+(1-x) E_{12}
$$

The replicator dynamics equation of the proportion $x$ for the government departments is

$$
\begin{aligned}
U_{1}(x) & =x(1-x)\left(E_{11}-E_{12}\right) \\
& =x(1-x)\left[z\left(r_{1}-r_{2}\right)-y\left(\alpha C_{1}+\beta C_{2}+S\right)+W+S+\alpha C_{1}-\gamma C_{3}\right]
\end{aligned}
$$

Supposing that $E_{21}$ represents the expected earnings of enterprises that utilize production strategy, $E_{22}$ represents the expected earnings of enterprises that utilize non-production, and $\bar{E}_{2}$ represents the expected earnings of enterprises that utilize the both strategies, where:

$$
\begin{gathered}
E_{21}=x z b_{1}+x(1-z) b_{5}+(1-x) z b_{3}+(1-x)(1-z) b_{7} \\
E_{22}=x z b_{2}+x(1-z) b_{6}+(1-x) z b_{4}+(1-x)(1-z) b_{8} \\
E_{2}=y E_{21}+(1-y) E_{22}
\end{gathered}
$$

The replicator dynamics equation of the proportion $y$ for the enterprises is

$$
\begin{aligned}
U_{2}(y) & =y(1-y)\left(E_{21}-E_{22}\right) \\
& =y(1-y)\left[x(T-S)+z\left(F_{2}-F_{3}\right)+R_{1}+S-R_{2}-c\right]
\end{aligned}
$$

Similarly, $E_{31}$ and $E_{32}$ are the expected earnings of financial institutions, represent the strategy participation and non-participation, respectively, and that $\bar{E}_{3}$ indicates the expected earnings of financial institutions that adopt the two strategies. Then,

$$
\begin{aligned}
& E_{31}=x y c_{1}+x(1-y) c_{2}+(1-x) y c_{3}+(1-x)(1-y) c_{4} \\
& E_{32}=x y c_{5}+x(1-y) c_{6}+(1-x) y c_{7}+(1-x)(1-y) c_{8}
\end{aligned}
$$


The Strategy Options of Energy-Saving and Environmental Protection Industry under Incomplete Information

$$
\bar{E}_{3}=z E_{31}+(1-z) E_{32}
$$

The replicator dynamics equation of the proportion $y$ for the enterprises is

$$
\begin{aligned}
U_{3}(z) & =z(1-z)\left(E_{31}-E_{32}\right) \\
& =z(1-z)\left[y\left(C_{5}-C_{4}\right)+x P_{2}+P_{1}-C_{5}\right]
\end{aligned}
$$

\begin{tabular}{|c|c|c|c|c|}
\hline & \multicolumn{2}{|l|}{$\begin{array}{c}\text { Positive } \\
(x)\end{array}$} & \multicolumn{2}{|l|}{$\begin{array}{c}\text { Negative } \\
(1-x)\end{array}$} \\
\hline & $\begin{array}{c}\text { Production } \\
(y)\end{array}$ & $\begin{array}{c}\text { Non-production } \\
(1-y)\end{array}$ & $\begin{array}{c}\text { Production } \\
(y)\end{array}$ & $\begin{array}{c}\text { Non-production } \\
(1-y)\end{array}$ \\
\hline Participation $(z)$ & $\left(a_{1}, b_{1}, c_{1}\right)$ & $\left(a_{2}, b_{2}, c_{2}\right)$ & $\left(a_{3}, b_{3}, c_{3}\right)$ & $\left(\mathrm{a}_{4}, \mathrm{~b}_{4}, \mathrm{c}_{4}\right)$ \\
\hline $\begin{array}{c}\text { Non-participatio } \\
\mathrm{n}(1-z)\end{array}$ & $\left(a_{5}, b_{5}, c_{5}\right)$ & $\left(a_{6}, b_{6}, c_{6}\right)$ & $\left(\mathrm{a}_{7}, \mathrm{~b}_{7}, \mathrm{c}_{7}\right)$ & $\left(\mathrm{a}_{8}, \mathrm{~b}_{8}, \mathrm{c}_{8}\right)$ \\
\hline
\end{tabular}

Table 2

The payoff matrix of three players

\subsection{The stability analysis of equilibrium strategy}

We can build a replicator dynamic system, namely:

$$
\left.\begin{array}{l}
U_{1}^{\prime}(x)=(1-2 x)\left[z\left(r_{1}-r_{2}\right)-y\left(\alpha C_{1}+\beta C_{2}+S\right)+W+S+\alpha C_{1}-\gamma C_{3}\right] \\
U_{2}^{\prime}(y)=(1-2 y)\left[x(T-S)+z\left(F_{2}-F_{3}\right)+R_{1}+S-R_{2}-c\right] \\
U_{3}^{\prime}(z)=(1-2 z)\left[y\left(C_{5}-C_{4}\right)+x P_{2}+P_{1}-C_{5}\right]
\end{array}\right\}
$$

In the above replicator dynamic system, the equilibrium points in

$R=\{(x, y, z) \mid 0 \leq x \leq 1,0 \leq y \leq 1,0 \leq z \leq 1\}$ include

$A_{0}(0,0,0), A_{1}(1,0,0), A_{2}(1,1,0), A_{3}(0,1,0), A_{4}(0,1,1), A_{5}(1,1,1), A_{6}(1,0,1), A_{7}(0,0,1)$

and $E\left(x^{*}, y^{*}, z^{*}\right)$. Obtaining an evolutionary stability strategy requires $U_{\mathrm{i}}(x) \prec 0$,

$U_{2}^{\prime}(y) \prec 0, U_{3}^{\prime}(z) \prec 0$.

As for government, it can be inferred from Eq. (12):

(1)When $z\left(r_{1}-r_{2}\right)-y\left(\alpha C_{1}+\beta C_{2}+S\right)+W+S+\alpha C_{1}-\gamma C_{3}=0, U_{1}(x) \equiv 0$, and all DOI: $10.24818 / 18423264 / 52.3 .18 .13$ 
levels are in a stable state; the stability of $x$ depends on this boundary. When $z\left(r_{1}-r_{2}\right)-y\left(\alpha C_{1}+\beta C_{2}+S\right)+W+S+\alpha C_{1}-\gamma C_{3} \neq 0, \quad x=0$ and $x=1$ are the two stability states of $x$.

(2)When $z\left(r_{1}-r_{2}\right)-y\left(\alpha C_{1}+\beta C_{2}+S\right)+W+S+\alpha C_{1}-\gamma C_{3} \prec 0$, namely $y \succ \frac{z\left(r_{1}-r_{2}\right)+W+S+\alpha C_{1}-\gamma C_{3}}{\alpha C_{1}+\beta C_{2}+S}, U_{1}(x)_{(x=0)} \prec 0, U_{1}(x)_{(x=1)} \succ 0$; therefore $x=0$ is the evolutionary stability strategy.

(3)When $z\left(r_{1}-r_{2}\right)-y\left(\alpha C_{1}+\beta C_{2}+S\right)+W+S+\alpha C_{1}-\gamma C_{3} \succ 0$, also $y \prec \frac{z\left(r_{1}-r_{2}\right)+W+S+\alpha C_{1}-\gamma C_{3}}{\alpha C_{1}+\beta C_{2}+S}, U_{1}(x)_{(x=0)} \succ 0, U_{1}(x)_{(x=1)} \prec 0$, and $x=1$ is the evolutionary stability strategy. The dynamics trend schematic diagram of government is shown in Figure 2:
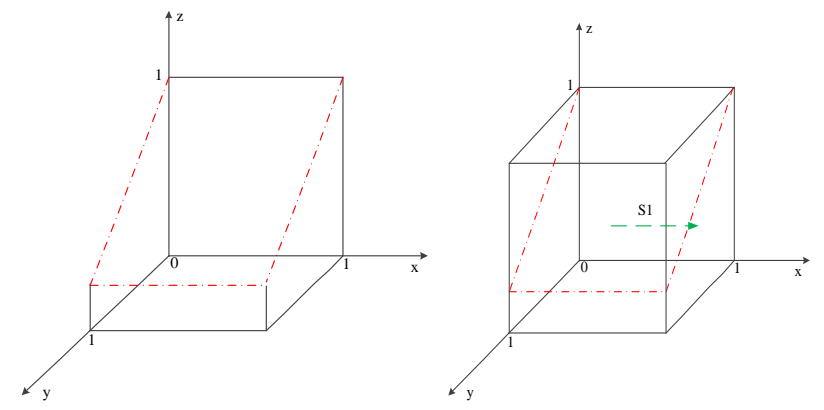

$z\left(r_{1}-r_{2}\right)-y\left(\alpha C_{1}+\beta C_{2}+S\right)+W+S+\alpha C_{1}-\gamma C_{3}=0 z\left(r_{1}-r_{2}\right)-y\left(\alpha C_{1}+\beta C_{2}+S\right)+W+S+\alpha C_{1}-\gamma C_{3} \succ 0$

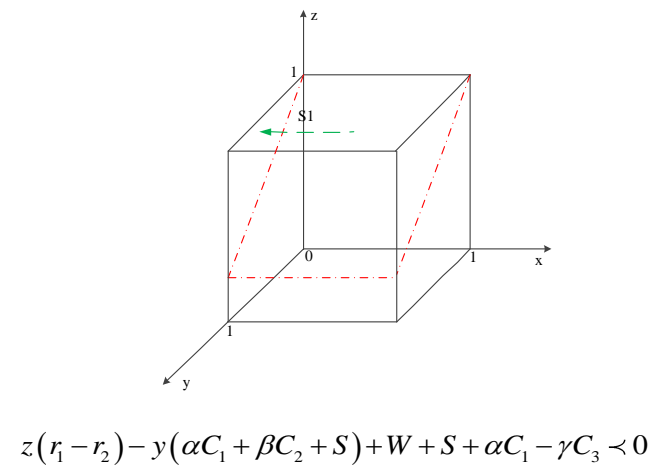

Figure 2. Dynamics trend schematic diagram of government

As for enterprises, it can be inferred from Eq. (16): 
The Strategy Options of Energy-Saving and Environmental Protection Industry under Incomplete Information

(1) When $x(T-S)+z\left(F_{2}-F_{3}\right)+R_{1}+S-R_{2}-c=0, U_{2}(y) \equiv 0$, all levels are in a stable state; the stability of $y$ needs to be solved, therefore, depends on this boundary. When $x(T-S)+z\left(F_{2}-F_{3}\right)+R_{1}+S-R_{2}-c \neq 0$, if we let $U_{2}(y)=0$, then $y=0$ and $y=1$ are the ways of $U_{2}(y)=0$.

(2) When $x(T-S)+z\left(F_{2}-F_{3}\right)+R_{1}+S-R_{2}-c \prec 0, \quad z \prec \frac{R_{2}+c+x(S-T)-R_{1}-S}{F_{2}-F_{3}}$, $U_{2}^{\prime}(y)_{(y=0)} \prec 0, U_{2}^{\prime}(y)_{(y=1)} \succ 0$. Thus $y=0$ is the evolutionary stability strategy.

(3) When $x(T-S)+z\left(F_{2}-F_{3}\right)+R_{1}+S-R_{2}-c \succ 0, \quad z \succ \frac{R_{2}+c+x(S-T)-R_{1}-S}{F_{2}-F_{3}}$, $U_{2}^{\prime}(y)_{(y=0)} \succ 0, \quad U_{2}^{\prime}(y)_{(y=1)} \prec 0$. Obviously, $y=1$ is the evolutionary stability strategy, and the dynamics trend schematic diagram of enterprises is shown in Fig. 3:

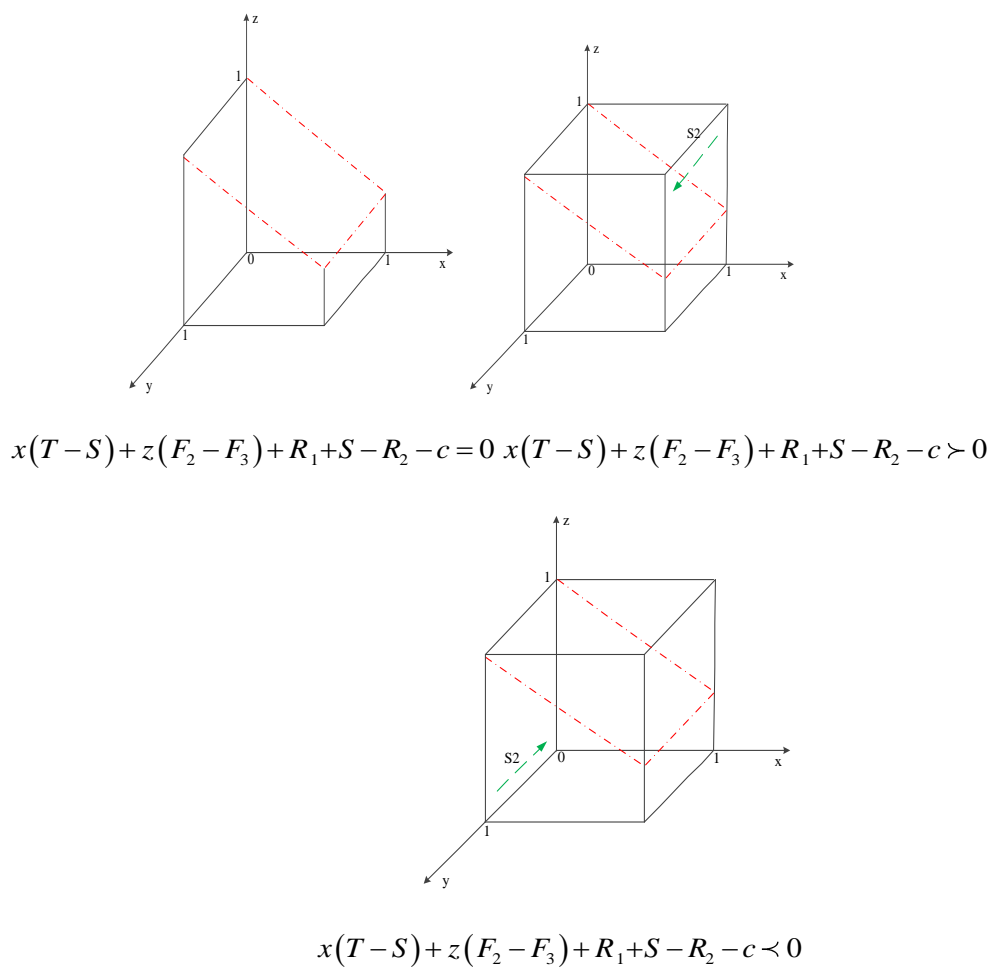

Figure 3. Dynamics trend schematic diagram of enterprises

DOI: $10.24818 / 18423264 / 52.3 .18 .13$ 
As for financial institutions, it can be inferred from Eq. (20):

(1) When $y\left(C_{5}-C_{4}\right)+x P_{2}+P_{1}-C_{5}=0, U_{3}(z) \equiv 0$, all levels are in a stable state; the stability of $z$ depends on this boundary. When $y\left(C_{5}-C_{4}\right)+x P_{2}+P_{1}-C_{5} \neq 0$, $z=0$ and $z=1$ are the two answers of $U_{3}(z)=0$.

(2) When $y\left(C_{5}-C_{4}\right)+x P_{2}+P_{1}-C_{5} \prec 0, \quad x \prec \frac{y C_{4}+C_{5}-y C_{5}-P_{1}}{P_{2}}, \quad U_{3}^{\prime}(z)_{(z=0)} \prec 0$, $U_{3}^{\prime}(z)_{(z=1)} \succ 0$. So $z=0$ is the evolutionary stability strategy.

(3) When $y\left(C_{5}-C_{4}\right)+x P_{2}+P_{1}-C_{5} \succ 0, \quad x \succ \frac{y C_{4}+C_{5}-y C_{5}-P_{1}}{P_{2}}, \quad U_{3}^{\prime}(z)_{(z=0)} \succ 0$, $U_{3}^{\prime}(z)_{(z=1)} \prec 0$. Obviously, $z=1$ is the evolutionary stability strategy, and the dynamics trend schematic diagram of financial institutions is shown in Figure 4:

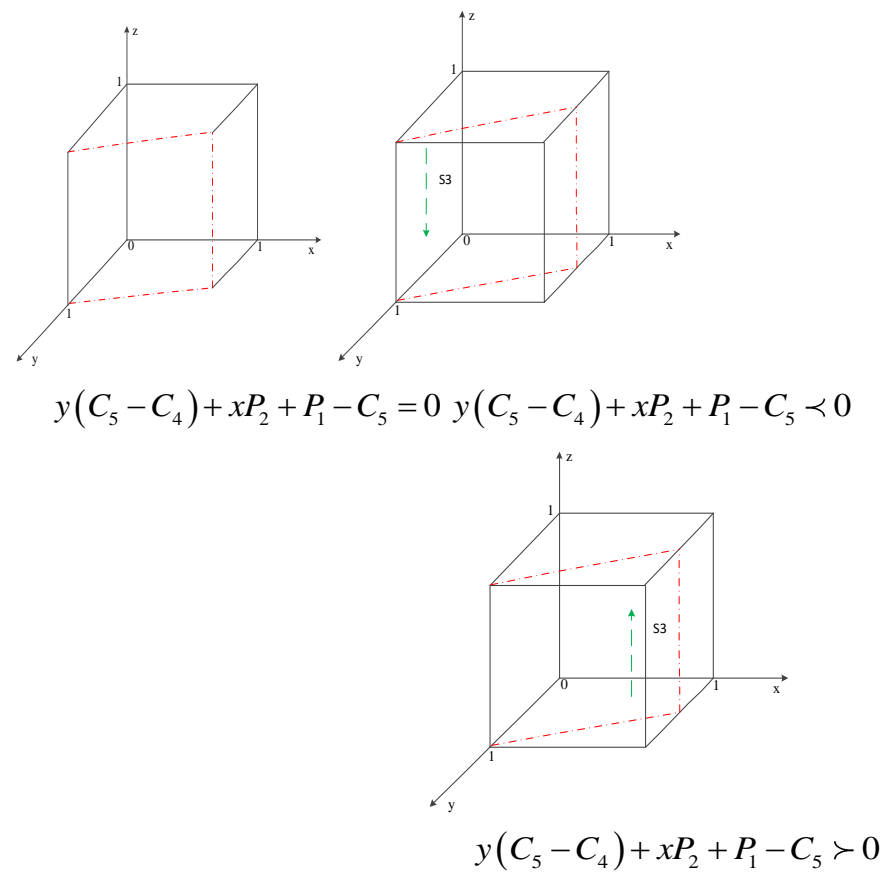

Figure 4. Dynamics trend schematic diagram of financial institutions 
The Strategy Options of Energy-Saving and Environmental Protection Industry under Incomplete Information

\subsection{Major implications}

From the above results, four major implications can be summarized.

(1) When $y \prec \frac{z\left(r_{1}-r_{2}\right)+W+S+\alpha C_{1}-\gamma C_{3}}{\alpha C_{1}+\beta C_{2}+S}, x=1$ is the evolutionary stable strategy, namely government selects positive strategy, which means that the government needs to increase the supervision costs, and the penalty imposed on enterprises without producing green products.

(2) When $z \succ \frac{R_{2}+c+x(S-T)-R_{1}-S}{F_{2}-F_{3}}, y=1$ is the evolutionary stable strategy.

On one hand, the increased benefits for enterprises to implement production strategy. On the other hand, government should expect to enforce stricter penalties for non-production enterprises. Finally, financial institutions should select participation strategy and decrease the enterprises "free rider behavior".

(3) When $x \succ \frac{y C_{4}+C_{5}-y C_{5}-P_{1}}{P_{2}}, z=1$ is the evolutionary stable strategy. We should increase the extra benefits of financial institutions selecting participation strategy, and the reputation costs when financial institutions select non-participation under the government adopts positive strategy.

(4) Different initial games lead to different equilibriums. Which strategy will be chosen eventually depends upon how much percentage of various strategies is chosen initial. In the long run, $(x, y, z)=(1,1,1)$ is a perfect equilibrium state . To achieve this long-term goal, the government should insist on both incentives and regulations for the enterprise and financial institutions. Financial institutions should positively participation energy-saving and environmental protection activities. Finally, the enterprises should be filled with unbounded confidence, and produce green products. All in all, government, enterprises and financial institutions should focus attention on long-time benefits.

\section{Conclusions and policy implications}

About the researches of energy-saving and environmental protection industrial innovation just focus on the two stakeholders (enterprises and consumers, or enterprises and government) evaluation, and few of them can further evaluate the possibility of coordination between the three stakeholders (included financial institutions, government and enterprises). Especially, financial institutions play a key role in the energy-saving and environmental protection industrial development.

DOI: $10.24818 / 18423264 / 52.3 .18 .13$ 
This paper fills this research gap through evolutionary game theory and the replicator dynamics model. We build a tripartite evolutionary game model, including the government, enterprises and financial institutions, and examine how different types of strategies of the stakeholders evolve dynamically under limited rational conditions. According to the game analysis and results, we can summarizeas follows: Firstly, the government needs to increase the supervision costs, and enforce stricter penalties for non-production enterprises. Therefore, the proper constrained plan can be drawn up according to the actual industrial conditions and present economic situation. In china, in the long run, the central and local government should insist on both incentives and regulations for the enterprises and financial institutions. Especially, government should set up and improve green financial system. Secondly, the enterprises should produce green products, and shift traditional production system. Finally, the financial institutions should select participation strategy, for example, creating green credit, green bonds, green insurance and green fund. Energy-saving and environmental protection industry should be advocated all the time.

This study can help multi-stakeholders to develop clear visions in the long run industrial innovation. Also, there are some limited aspects that should be investigated in the future work, such as the other stakeholders, the other influence factors. We will explore in the future.

\section{REFERENCES}

[1] Bi, K., Huang, P., Ye, H. (2015), Risk Identification, Evaluation and Response of Low-Carbon Technological Innovation under the Global Value Chain: A Case of the Chinese Manufacturing Industry. Technol. Forecast. Soc. Chang. 100, 238-248;

[2]Ben Ma, Y. H. Yu. (2017), Industrial Structure, Energy-Saving Regulations and Energy Intensity: Evidence from Chinese Cities. J. Clean. Prod.141, 1539-1547;

[3]Bao, H.J., Peng, Y., Ablanedo-Rosas, J.H., Gao, H.M. (2015), An Alternative Incomplete Information Bargaining Model for Identifying the Reasonable Concession Period of A BOT Project. Int. J. Proj. Manag. 33, 1151-1159;

[4]Bin Wu, P. F. Liu, X. F. Xu. (2017), An Evolutionary Analysis of Low-Carbon Strategies Based on the Government-Enterprise Game in the Complex Network Context. J. Clean. Prod. 141,168-179;

[5]Cole, M.A., Elliott, R.J., Okubo, T., Zhou, Y. (2013), The Carbon Dioxide 
The Strategy Options of Energy-Saving and Environmental Protection Industry under Incomplete Information

Emissions of Firms: A Spatial Analysis. J. Environ. Econ.Manag.65, 290-309;

[6]Choi, Y. (2015), Introduction to the Special Issue on "Sustainable E-Governance In Northeast-Asia: Challenges Or Sustainable Innovation". Technol. Forecast. Soc. Chang. 96, 1-3;

[7]Constantinos Taliotis, Emanuele Taibi, Mark Howells, Holger Rogner, Manuel Welsch. (2017), Renewable Energy Technology Integration for the Island of Cyprus: A Cost-Optimization Approach. Energy.137,31-41;

[8]Fang GC, Tian LX, Sun M, Fu M. (2012), Analysis and Application of a Novel Three-Dimensional Energy-Saving and Emission-Reduction Dynamic Evolution System. Energy.40,291-9;

[9]Jing-Yu Liu, Yan Xia, Ying Fan, Shih-Mo Lin, J. Wu. (2017), Assessment of a Green Credit Policy Aimed at Energy-Intensive Industries in China Based on a Financial CGE Model. J. Clean. Prod.163, 293-302;

[10]Kathuria, V.(2007), Informal Regulation of Pollution in a Developing Country: Evidence from India. Ecol. Econ. 63, 403-417;

[11]Langpap. C., Shimshack. J.P. (2010), Private Citizen Suits and Public Enforcement: Substitutes or Complements. J. Environ. Econ.Manag.65, 290-309;

[12]Lian, T., Ma, T., Gao, J., Wu, Y.(2016), The Effects of Environmental Regulation on the Industrial Location of China's Manufacturing. Nat. Hazards. 80, 1381-1403;

[13]Lin, R.J., Tan, K.H., Geng, Y. (2013), Market Demand, Green Product Innovation, and Firm Performance: Evidence from Vietnam Motorcycle Industry. J. Clean. Prod. 40, 101-107;

[14]Lorek, S., Spangenberg, J.H.(2014), Sustainable Consumption within a Sustainable Economy-Beyond Green Growth and Green Economies. J. Clean. Prod. 63, 33-44;

[15]Myeong, S., Kwon, Y., Seo, H. (2014), Sustainable E-Governance: The Relationship among Trust, Digital Divide, and E-Government. Sustainability. 6 , 6049-6069;

[16]Ping. J.,Xin, M., Gang. Li.(2015), Developing Green Purchasing Relationships for the Manufacturing Industry: An Evolutionary Game Theory Perspective. Int. J. Prod. Econ. 166, 155-162;

[17]Pasquale Marcello Falcone, Piergiuseppe Morone, Edgardo Sica.(2017), Greening of the Financial System and Fuelling a Sustainability Transition: A Discursive Approach to Assess Landscape Pressures on the Italian Financial

DOI: 10.24818/18423264/52.3.18.13 
System. Technol. Forecast. Soc. Change. 114, 119-137;

[18]Rui, Z., Xiao, Z., Jiao, H., Cheng, L.(2016), For the Sustainable Performance of the Carbon Reduction Labeling Policies under an Evolutionary Game Simulation. Technol. Forecast. Soc. Change.112, 262-274;

[19]Tian LX, Jin RL.(2012), Theoretical Exploration of Carbon Emissions Dynamic Evolutionary System and Evolutionary Scenario Analysis. Energy.40,376-86;

[20]X. F. Zhao, H. M. Li, Liang Wu, Ye Qi.(2014), Implementation of Energy-Saving Policies in China: How Local Governments Assisted Industrial Enterprises in Achieving Energy-Saving Targets. Energy policy. 66, 170-184;

[21]X. B. Liu, C. Wang, D. J. Niu, Sunhee Suk, C. K. Bao.(2015), An Analysis of Company Choice Preference to Carbon Tax Policy in China. J. Clean. Prod.103, 393-400;

[22]Xin Liang, Yi Peng, Geoffrey, Q. P. Shen. (2016), A Game Theory Based Analysis of Decision Making for Green Retrofit under Different Occupancy Types. J. Clean. Prod.137,1300-1312;

[23]Y. H. Tian, Kannan Govindan, Q. H. Zhu.(2014), A System Dynamics Model Based on Evolutionary Game Theory for Green Supply Chain Management Diffusion among Chinese Manufacturers. J. Clean. Prod. 80,96-105;

[24]Zhao, H.H., Gao, Q., Wu, Y.P., Wang, Y., Zhu, X.D.(2014), What Affects Green Consumer Behavior in China? A Case Study from Qingdao. J. Clean. Prod. 63, 143-151;

[25]Z.C. Guo, Z.X. Fu. (2010), Current Situation of Energy Consumption and Measures Taken for Energy Saving in the Iron and Steel Industry in China. Energy.35,4356-4360. 